Trivent Publishing

(C) The Authors, 2016

Available online at http://trivent-publishing.eu/

Series: Philosophy, Communication, Media Sciences

Volume: Communication Today: An Overview from Online Journalism to Applied Philosophy

\title{
Pragmatic Approaches in the Analysis of the Political Discourse
}

\author{
Bianca Drămnescu \\ Communication and Public Relations Department, West University of Timișoara, Romania \\ b.dramnescu@gmail.com
}

\begin{abstract}
Pragmatics in discourse analysis plays a decisive role in the creation of effective political communication strategies. Therefore, speech lies at the junction of rhetoric, linguistics and politics. This study focuses on characterizing the main approaches in pragmatic discourse analysis based on a comparative analysis of studies by international specialists. The intension in communication represents a pragmatic element which plays a decisive role at the time for the communication process. Speech is a central point of interest for social and political spheres. Conceptions about language in association with pragmatics turn the usual rhetoric into a speech activity coordinated by normative linguistic dimensions.
\end{abstract}

\section{Keywords}

Intentionality; pragmatics; discourse analysis; speech acts; political discourse

This is an Open Access article distributed in accordance with the Creative Commons Attribution Non Commercial (CC-BYNC-ND 4.0) license, which permits others to copy or share the article, provided original work is properly cited and that this is not done for commercial purposes. Users may not remix, transform, or build upon the material and may not distribute the modified material (http://creativecommons.org/licenses/by-nc/4.0/)

This work was cofinanced from the European Social Fund through the Sectoral Operational Programme Human Resources Development 2007-2013, project number POSDRU/159/1.5/S/140863, Competitive Researchers in Europe in the Field of Humanities and Socio-Economic Sciences. A Multi-regional Research Network.

DOI: $10.22618 /$ TP.PCMS.20164.349005 


\section{Introduction}

Generally, pragmatics is a method of analysing the relation between signs and their interpretation. Throughout history, the concept of interpretation has changed. Discourse analysis is a relatively new concept, being a branch of pragmatics. It can be interpreted in various ways, both as a tool and as a discipline. Everything we do in our lives is affected by our thought and the language we use. There are several situations when we become "the prisoners" of our own minds. We think in a certain way, but we speak differently. This problem has been the topic of research not only for philosophy and psychology, but also for communication sciences. The language people use is manner of creating a personal image. This means of personal branding became an important step in politics which in turn brought politicians closer to citizens. Discourse plays an important role in managing a political brand. Words are power and power lies within words. Everything a person says can be used to his/her benefit or detriment. In this context, the problem is the difference between what is actually said and what it meant to be said. In this paper, the author studies the intentions in discourse as an important pragmatic element. First of all, the meaning of a sentence is interpreted by the way it is said and then by its intended meanings.

When discussing pragmatic theory, the principles of rationality must be mentioned. Rationality is interpreted differently all over the world because of various backgrounds and cultures.

\section{Pragmatics. Literature review}

Throughout history, pragmatics has represented an important part in the study of language because of its interdisciplinary character connecting the fields of philosophy, psychology and language studies. The most important researchers focusing on pragmatics were S. Pierce, R. Carnap, and C. Morris who investigated the relationship between signs and the way they are used. The analysis of their results mentioned that the concept of pragmatics must change into two sub-disciplines: "sociolinguistic and discourse analysis." " The purpose of the study of pragmatics is to analyse the context-dependent meaning of deixis, with the spoken word as the most important element in interpreting sentences. Levinson states that deixis represents a phenomenon in which linguistic expressions are dependent on the interpretation of its context. The interpretation of deixis is also dependent on the expression of time. If the present time is the context, it has to be clearly stated in the sentence, so the words used have to be related to the moment of speaking. The author includes in pragmatics the presupposition that in speech there are some "encoded backgrounds" that are questioned but the author do not mentioned them in the sentence. The language has "power" to create mental figures. The third and, in

\footnotetext{
${ }^{1}$ Stephen C. Levinson, Pragmatics (Cambridge: Cambridge University Press, 1983), 3-10.
} 
my opinion, the most important aspect of the field of pragmatics focuses on speech acts. In Austin's well-known paper, How to do things with words ${ }^{2}$ the author elucidated the mystery of power of words by creating the concept of "speech acts." Austin stated that words can have illocutionary, locutionary, and perlocutionary force. Speech contributes to the context in which the conversation is taking place by creating context. To create a speech act, we must have a context-dependence.

Traditionally, pragmatics is separated from semantics. In regards to this aspect, Leech ${ }^{3}$ has an opposing opinion which states that pragmatics and semantics are separated by complementary and interrelated fields of study and that highlights the difficulty of justifying their separation in an objective way. In my opinion, the most representative way of interpreting a verbal utterance is the study of speech acts.

In everyday life, the concept of "speech" is common among various fields, particularly in politics. Politicians use this method of communication to convey information to citizens and to maintain a strong link between state representatives (i.e. state power) and citizens.

The problem of political discourse has been investigated by Romanian researcher Constantin Sălăvăstru. "When you talk about any problem to influence the choice and action, the receiver when choosing issues just about its ability to influence more strongly a particular audience, when you can change at will the thematically register according to the context discursive and enhanced possibilities for manipulation public, then you really handle the tool enthralled by the action of otherness. Other types of speech does not have this advantage: scientific discourse cannot talk about anything unless it is confined to a particular theme (depending on what you want to show the speaker), religious speech is unable to talk about anything but confined to a certain theme (moreover, it is really quite limited in terms of the issue), and even philosophical discourse, which I believe the maximum capacity issue has certain favourite themes obstinately pursued."

Political discourse is the message through any politician who is normally a party member or candidate representative of a political function. Feedback is usually delayed in acts of communication between the transmitter and the receiver which take place in a political context. This can be evident in voting or statements made by preference polls.

In a communication situation, subjectivity plays a central role; political discourse can influence this to some extent. To give an authentic character, the discourse implicitly contains subjective elements, for even when the topics of speech are objective or general, subjectivity is felt. But this can be a form of manipulation.

Constantin Sălăvăstru has proposed a list of traits determinant of political discourse:

\footnotetext{
2 John Langshaw Austin, Sorana Corneanu, Vlad Alexandrescu. Cum să faci lucruri cu vorbe [How to do things with words] (Piteşti: Paralela 45, 2005), 95-106.

${ }^{3}$ Geoffrey N. Leech, The principles of pragmatics (London: Longman Linguistic Library, 1983), 6-7.

${ }^{4}$ Constantin Sălăvăstru, Discursul puterii [The discourse of power] (Iaşi: Institutul European, 1999), 21-22.
} 
"1. Intentional ambiguity of the political discourse

2. The imperative nature of the political discourse

3. The polemical nature of the political discourse" ${ }^{5}$

First in this category, the author discusses the "ambiguity of the word" as a tool for persuading the audience. It cannot be removed from any speech and its aim is pursuit of self-interest. By this method, chances are recipients follow the ideas set out in the speech and act accordingly. In terms of policy, action may be materialized by voting.

Political discourse contains a hidden character understood by the author to be more informative than its content. In this case the ideological nature of discourse must be mentioned. A speech like this is not honest and reality is distorted intentionally.

The mandatory nature of political discourse refers to locutionary, illocutionary, and perlocutionary speech acts shown in studies of Austin and Searle. Likewise, Sălăvăstru specifies that in order to create a good speech there must be mentioned a few steps such as: "the description, the assessment, and prescription." ${ }^{\prime 6}$ Such speech must have a descriptive part where the author will inform the audience which aspect of reality in the speech is to be evaluated. Later this assessment must contain information that can tell the audience what to do with the legitimacy of power. In other words, the audience is included in relation to the mandatory nature of the political discourse.

The character of polemical discourse refers to power in terms of the manner in which ideas attack others. In short, speech contains aspects of support and rejection.

Regarding political language, I believe that linguistic relativity is one of the most important elements. This is sometimes seen as an American invention but there is a rich British and Continental heritage behind it. John Locke ${ }^{7}$ explicitly does not believe that English political and legal ideas could be translated into other languages. Most followers of language studies would associate linguistic relativity with the work of Edward Sapir (1884-1939) and his student Benjamin Lee Whorf (18971941) who created the conventional Sapir-Whorf hypothesis. Sapir and Whorf were asked if cognitive content lies within conceptual systems buried in individual languages, can one ever efficiently transfer a sense of community discourse to another person? "Is it possible that keyword policy such as constitution, legislature, citizen, country, political party and legitimacy have a specific culture that they cannot be accurately reproduced in languages apart from the target languages?". The researchers that accepted the Sapir-Whorf hypothesis argue that the language we speak affects how we perceive reality, though it does not control our reality absolutely.

\footnotetext{
${ }^{5}$ Ibidem, 76-92.

${ }^{6}$ Ibidem, 100-110

${ }^{7}$ In Richard Oliver Collin, "Moving political meaning across linguistic frontiers," in Political Studies (2013): 285.

${ }^{8}$ Ibidem.
} 
In the analysis of political discourse, the relationship between how thought and language are designed to create reality is often brought into question. I mentioned earlier that man creates reality through language. But the question that arises is which methods affect the thought process the most? The answer to this question could be manipulation techniques known in the vernacular as "brainwashing". The link between language and thinking can be interpreted in terms of the Sapir-Whorf hypothesis. Rodica Zafiu believes that "The link between reason and language - highlighted by the so-called Sapir-Whorf hypothesis - implies that it is easier to imagine what is already regulated by language, that it is easier to use notions which already have well-established words and expressions. However, one cannot demonstrate an extreme statement such as: <One cannot reason a notion which is not regulated by language $>$."

In a certain sense it would be problematic to see linguists divided into followers of rigid principles squaring off against partisans of cultural relativism. Some researchers are optimistic on this principle because it considers that some complex meanings can cross linguistic borders. Relativistic approaches emphasize that the meaning of words are "stuck" in a particular language/culture and cannot easily make the transition into another language.

Language comprises political events and developments in which people live; in this way, Edelman believes that "political language is the political reality." 10 Political developments and language are ambiguous because aspects of the events, leaders, and policies affect final decisions. Even when there is a reasonable consensus on what happened or what was said, there are contradictory hypotheses about the causes of evens and the consequences of courses of action.

Political language that generates and reinforces beliefs about who are allies and who are enemies is the political scene. Language often evokes a belief that certain groups are inherently bad, even if scientific language suggests that they are scapegoats rather than enemies. Countless victims of discrimination testify to the power of language in particular situations which evoke a political world where persecution is justified, even while the same words mean gross injustice to different people in other situations. Language which rationalizes hardship for people who do no harm applies very much to those who are already disadvantaged. This highlights a critical function in linguistic politics; it helps maintain inequalities created by unequal resources, status and power.

In political language analysis, another important point is the language of promises. Edelman ${ }^{11}$ believes that promises which political actors make illustrate policy objectives they aim to achieve and illustrates the meaning of language constructs similar to what people live within their own subjective experience. Political language largely consists of promises about future benefits that will result from

\footnotetext{
${ }^{9}$ Rodica Zafiu, Language and politics?(Bucharest: Bucharest University Edition, 2007), 30.

${ }^{10}$ Murray Edelman, "Political language and political reality," in Political Studies 18 (1985): 10.

${ }^{11}$ Ibidem.
} 
any cause the speaker champions. Promises of peace, prosperity, and other assets invert fears in order to win support for actions portraying a brighter future.

Following the correlation between language and the creation of reality, Gregory Shafer ${ }^{12}$ argues that words, when used together with metaphors and in a repetitive context, can create a reality that serves politicians while undermining real progress at the same time. Shafer also cites that Gramsci argues that political language is the quintessence of deception. The deception can become the essnce of the political language. In general, the political actor often begins his speech by trying to create fear among the audience. In this way, politicians can successfully design simplistic dichotomies which the constituents consume. They use language-based artifice rather than communication.

On the other hand, David Parkin ${ }^{13}$ believes it is already clear how many scientists have studied explicitly political language and will continue to benefit from ethnographers studying performative attributes in the artistic and metaphorical use of language.

Rodica Zafiu offers another point of view; the "current political language - not only in Romania exhibits a strong tendency to mix registries, resorting to familiar elements that facilitate (through accessibility and emotional values) communication with a wider audience."14

\section{Conclusions}

The most important pragmatic reflections seen in political discourse are "speech acts" because the discourse implies immediate actions. The words used in speech can have an extreme impact on the way that the future events can happen. These are promised, declared statements which make a radical change of perspective. Sentence are not made in isolation, but rather are context-dependent in their meaning. The interpretation of any sentence depends on the interpretation of the relationship between contexts.

The problem of intentionality can be interpreted as a mental representation of what must be said and what is actually said. The words used have an intentional structure and a logical order.

As a conclusion to this paper, I wanted to summarize the ingredients used to create a discourse and how political speech is created in relation to context. At present, researchers of pragmatics and discourse analysis have only a partial understanding.

\footnotetext{
${ }^{12}$ Gregory Shafer, "Political language, democracy and the language art class," in English Journal 103.2 (2013): 30-32.

${ }^{13}$ David Parkin, "Political language," in Annual Review of Anthropology 13 (1984): 345-347.

${ }^{14}$ Rodica Zafiu, Language and politics?, 206.
} 


\section{References}

Austin, John. How to Do Things with Words. Oxford: Clarendon Press, 1962.

Brown, G., Gorge Yule. Discourse Analysis. Cambridge: Cambridge University, 1983.

Blakemore, D. Understanding Utterances: The Pragmatics of Natural Language. Oxford: Blackwell, 1990.

Collin, Richard Oliver. "Moving political meaning across linguistic frontiers." In Political Studies 61 (2013): 282-300.

Edelman, Murray. "Political language and political reality.” In Political Studies 18 (1985): 10-19.

Green, G. Pragmatics and Natural Understanding. Mahwah, NJ: Lawrence Erlbaum, 1989.

Leech, Geoffrey N. The principles of pragmatics. London: Longman Linguistic Library, 1983.

Levinson, Stephen C. Pragmatics. Cambridge: Cambridge University Press, 1983.

Mey, J. Pragmatics. An Introduction. Oxford: Blackwell, 1993.

Parkin, David. "Political Language." In Annual Review of Anthropology 13 (1984): 345-347.

Sălăvăstru, Constantin. Discursul puterii [The discourse of power]. Iaşi: European Institution, 1999.

Searle, J. Speech Acts. Cambridge: Cambridge University Press, 1968.

Shafer, Gregory. "Political language, democracy and the language art class." In English Journal 103.2 (2013): 30-32.

Zafiu, Rodica. Language and politics? Bucharest: Bucharest University Edition, 2007. 